\title{
Anthropometric evaluation of internal horizontal circulation environments
}

\author{
Sadi Seabra ${ }^{\mathrm{a}, *}$ and Bruno Barros ${ }^{\mathrm{b}}$ \\ ${ }^{a}$ Escola Técnica Estadual Agamenon Magalhães. Rua Joao de Barros, 1769. Encruzilhada, Recife - PE, Brasil. \\ CEP: 52021-180 \\ ${ }^{\mathrm{b}}$ Universidade Federal de Pernambuco- Núcleo de Design. Rodovia BR 104. KM 60 - Sítio Juriti - Caruaru - PE \\ - Brasil - CEP: 55002-970
}

\begin{abstract}
The relevant research is questioning the essence of the existence of an adequate internal circulation to human dimensions. The research was based on the method of anthropometric assessment of internal circulation de Barros (2009), which was applied in three different sizes of apartments in the city of Caruaru-PE. These apartments were evaluated through the floor plans and furniture layouts, suggested by the builders, with the use of anthropometric models in simulation of movement. The study found that traffic problems are not just a consequence of small rooms, but projects that do not bother to match the anthropometric measurements to the space environment.
\end{abstract}

Keywords: anthropometric assessment, internal circulation, housing design.

\section{Introduction}

For the development of the current study, we selected three types of apartments in the city of Caruaru, where, with the aim of obtaining more convincing data, we opted for the selection of apartments in very different social situations, the first being classified as Housing People. The second apartment meets the classification of the Standard Mean Standard and the last High. It is important to note that these classifications conform to the categorization of certain property taxes for that city.

The purpose of the analysis of three different apartments of social standards is the verification of a parameter of great influence on the quality of movement within an environment: the characterization of the layout of ambience (proposed by contractors) in relation to the size of the internal space built. Therefore, it would be seen to what extent the size of the apartment, plus the amount of furniture purchased (checked from the layout), can interfere with the internal horizontal circulation, and if that vary according to the social pattern of the user.
In evaluating the sites were listed where the circulation is inadequate to human dimensions, the most critical points, and the frequency with which they occur. Therefore the realization of the full proposal evaluation empty gaps on the issue of the built environment and in accordance with scientific standards, provide data for use by various sectors of industry and especially for the construction industry, benefiting from the projects of Engineers, Architects and Designers.

\section{Bibliographic}

\subsection{The anthropometry indoors}

Considerations advocated by Costa Filho et al (2003) [5] evaluated environments during use is a way to investigate mismatches with regard to manenvironment. To make recommendations to the system has to evaluate the activities of the residents in an apartment.

\footnotetext{
*Corresponding author. E-mail: sadi@sadiseabra.com
} 
According Bins Ely (2004) [2] the functional needs of users are directly linked to the demands of the tasks performed in the environment. For it must first consider the size and shape of space equipment and furniture, in the second flow of internal movement and disposal of the furniture and then the thermal comfort, light and sound.

The inner horizontal movement happens in the built environment where it operates a layout setting that, according to the Boueri (2009) [3] which in a lecture defined as the spatial layout of furniture and equipment included in the environment. Thus, the spatial arrangement will define the functionality of the use of the building.

The functional needs of users are directly linked to the demands of the tasks performed in the environment. To do this, should first consider the size and shape of space equipment and furniture: second, the flow of internal circulation and layout of the furniture and then, thermal comfort, light and acoustic (BINS ELY, 2004).

\section{Methodological procedures}

\subsection{The assessment anthropometric method for internal circulation spaces}

We used the Assessment Anthropometric Method for Internal Circulation Spaces, developed by Barros (2009) [1], this method makes an anthropometric assessment of the internal circulation of environments. He performs a simulation of the movement of users in certain environments, and in this simulation, chromatic diagnoses are made according to the level of problem found or fitness.

For this, the floor plans of apartment chosen were analyzed, keeping the scales of reality thanks to the actual proportions, without distortion. The blueprints contain the layout of the furniture and construction suggested by them were included anthropometric models.

To develop the analysis we used a CAD (Computer Aid Design). The handling was due to the overlap of human models in the plans with the final layout of ambience. The anthropometric model additionally inserted into the floor plan has, as suggested by Panero and Zelnik (2008) [5], measures adult human male.

Anthropometric models change its color due to the severity level of perceived inadequacy. We can see in the picture below, the representation of human models, their dimensions and field of movement.

Figure 1: Models set for the anthropometric method.

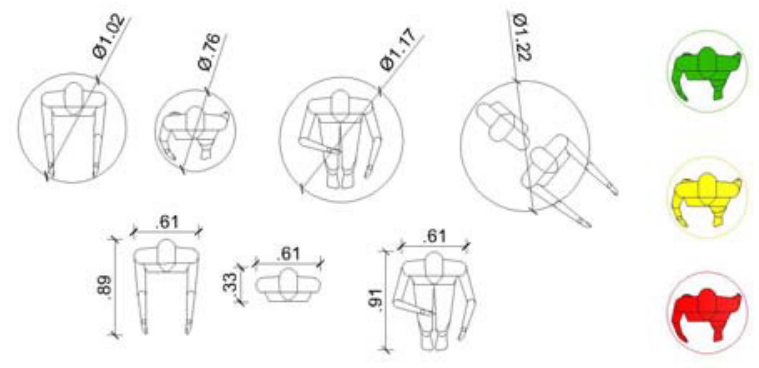

During simulated to evaluate the internal distribution of human models on the apartment plan in each environment. Always checking the relationship with the surrounding area comfortable to human movement, represented by the dashed circle around the anthropometric model.

The green anthropometric models for the assessment, were placed in environments where there is free mobility, digital yellow dummies were placed where the movement deserves characterized as areas of risk (physical barriers played in a circle around anthropometric dummy) and human red end models were placed where there are gaps in the project, ie, inappropriate situations (physical barriers played on the same anthropometric model).

\subsection{Objects of study selected}

The first object of study is selected from the apartment Portal Wasteland Classified according to Housing and property taxes, and is located in a subdivision COHAB typing. The housing unit has $47 \mathrm{~m}^{2}$ and is only equipped with two bedrooms, a room for two environments, a service area, combined with the kitchen and one toilet. We can see in the image that follows, the reproduction of the ground floor of that apartment with the suggested layout.

The second house belongs to the selected Alphaville Building, located in an upscale neighborhood in the city of Caruaru-PE. This apartment is classified according to city property taxes as the average standard. The housing unit has approximately $140 \mathrm{~m}^{2}$ and is equipped with a single bedroom, twobedroom suites, one room to three rooms, two balconies, a maid with bathroom, a pantry / kitchen and a social toilet. The following image gives the floor plan of the apartment of average standard. 
The third apartment building owned by Gabriella analyzed, also situated in a prime area of the city of Caruaru-PE. It has approximately $365 \mathrm{~m}^{2}$, one per floor. It is classified by the property tax as an apartment of high standard. You can see in the image below for the plan with the layout suggested by the developer. The apartment has three rooms, three suites and one master suite, library / office, two service rooms, pantry, laundry room, six bathrooms, kitchen and pantry.

\section{Presentation and discussion of results}

\subsection{Outcomes of the apartment people}

Were evaluated in the simulation of circulation in the apartment of the Portal of the Wasteland, where 37 points were included anthropometric models.

It was found that 10 simulation situations where appropriate anthropometric models appear in green, 9 situations that require attention or where the risk anthropometric models appear in yellow and 18 situations where inadequate anthropometric models appear in red.

In the picture below, shows the floor plan of the building under application of evaluation method, where you can see, clearly, all adjustments, inadequacies and risk points diagnosed.

Figure 2: Anthropometric assessment of the circulation of the apartment classified as Housing.

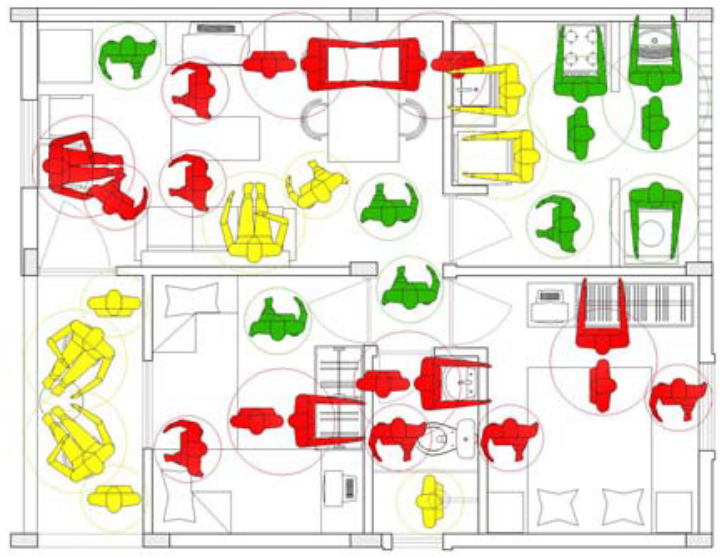

With these data, it was found that the assessment circulating in $27.03 \%$ of the situations are appropriate to the anthropometric factors, $24.32 \%$ require attention or generate a situation of risk and $48.65 \%$ of the cases are inadequate to human action.
Figure 3: graph of the results obtained in apartment housing.

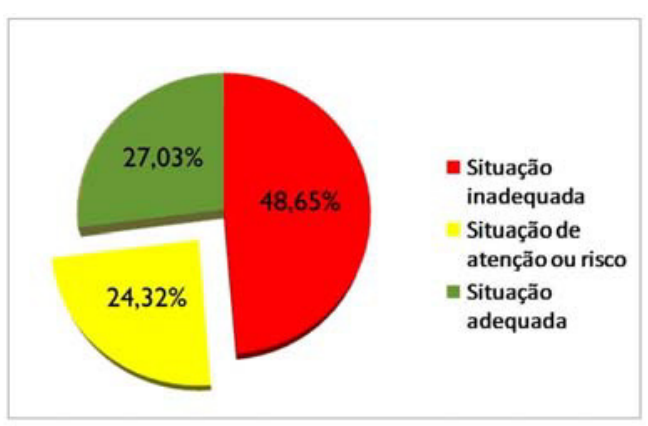

\subsection{Results obtained in the average standard apartment}

In the apartment building were evaluated Alphaville 77 points in the circulation where they were inserted anthropometric models. It was found that green anthropometric assessment models 26, which indicated that the circulation was adequate, 15 yellow anthropometric models which indicated that the movement demanded attention or generated risk models and 36 anthropometric pointed inappropriate situations.

In the picture below, shows the floor plan of building the average standard in applying the method. In the picture you can see the color of the diagnostic evaluation. 
Figure 4: graph of the results obtained in apartment housing.

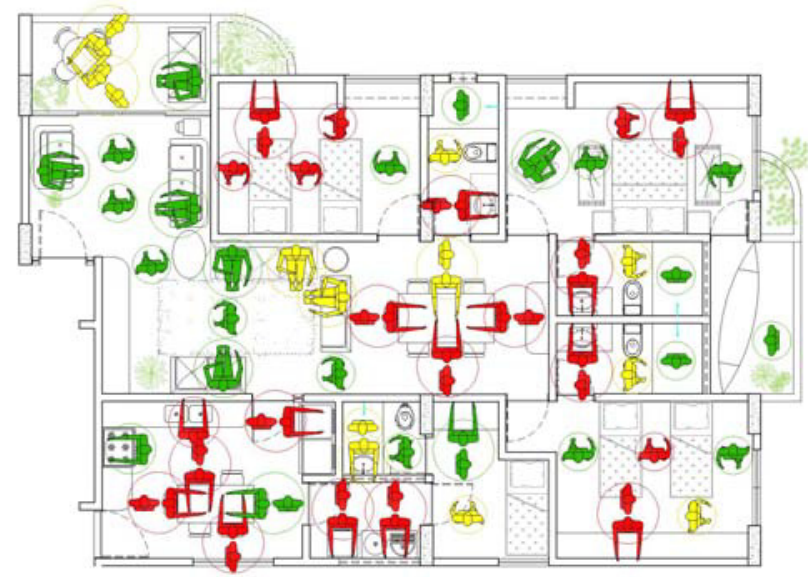

With this data analysis showed that $33.77 \%$ of the circulation of this apartment are suitable to anthropometric factors, $19.48 \%$ are at risk or attention and $46.75 \%$ are inadequate measures human.

Figure 5: graph of the results obtained in the apartment of average standard.

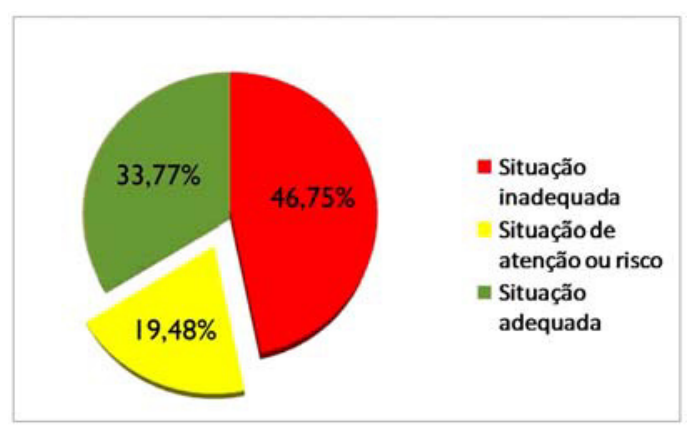

\subsection{Results Obtained in the apartment of high standard}

For the apartment building Gabriella 172 models were applied to evaluate anthropometric circulation. It was found 105 suitable cases this assessment, which are represented in the anthropometric models for green, 33 or risky situations that require attention, which are represented by models in yellow, and 34 inappropriate situations, which are represented in the anthropometric models by color red.

In the picture below, shows the floor plan of the building of high standard in applying the method of evaluation of internal horizontal movement.
Figure 6: Anthropometric assessment of the circulation of the apartment classified as high standard.

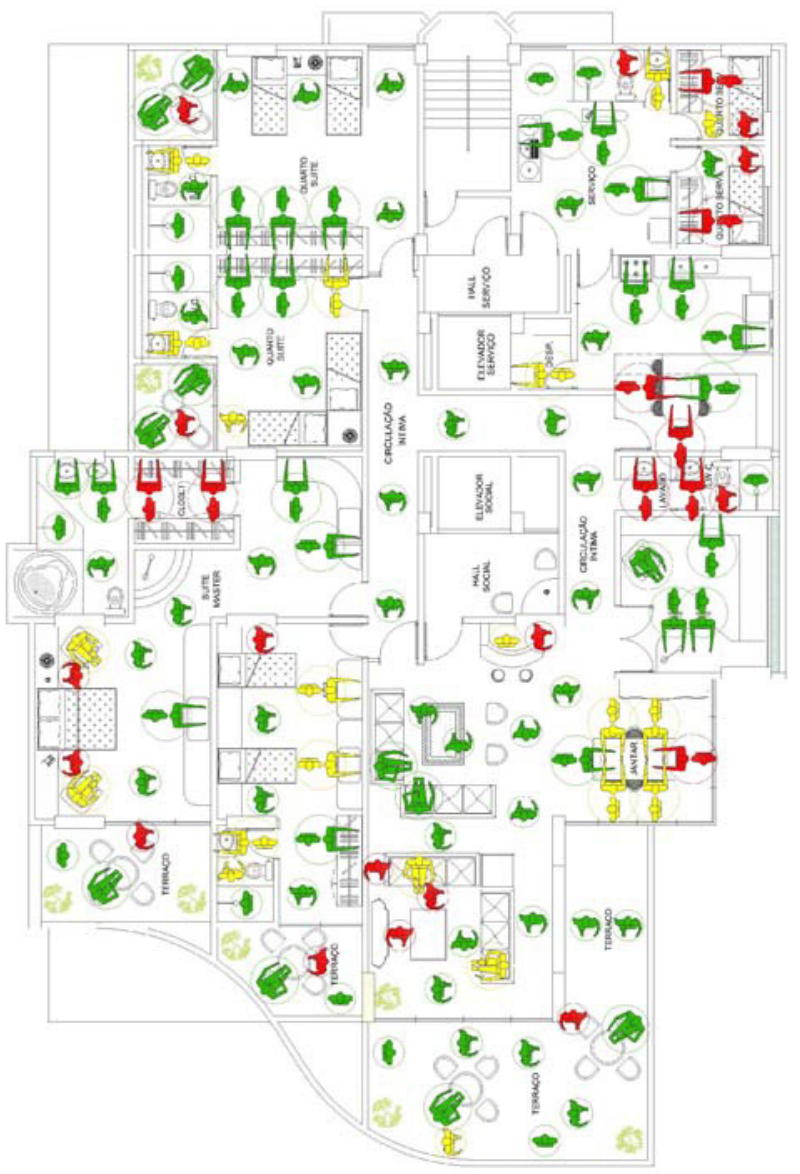

Through these data, it was found that the circulation in this apartment had $61.05 \%$ of situations appropriate to human action; $19.19 \%$ of situations that require attention or risk, and $19.76 \%$ of situations inadequate human factors (Figure 7 ). 
Figure 7: Graph of the results obtained in the apartment of high standard.

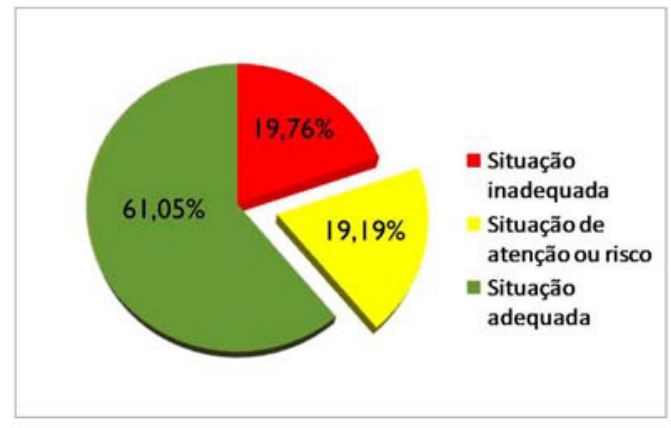

\subsection{Comparative analysis of the three selected apartments}

Analyzing the data obtained from the graphs of all apartments can be seen that the larger the apartment, the greater the number of areas of human movement appropriate measures. Likewise, the smaller the apartment, the greater the number of areas unsuitable for circulation, however, in situations of attention, it is clear that the three apartments was statistically about the same, as can be seen in the charts.

For the living room, it was noted that the causes of inadequacy are linked to movement between the coffee table and couch and attention is a situation of who is using the sofa. This situation just was not diagnosed by the average standard apartment, perhaps by the absence of the coffee table.

In the dining rooms and in the hearts and situations were perceived inadequacies of care for people trying to move the table while it is being used, this issue was noted in all apartments.

For kitchens, the circulation was well respected and popular in the apartment of high standard, however the average standard of the apartment was found that the movement is not according to human measures when considering the activities performed in this environment.

It was observed that in all the apartments, when using the wardrobe or closet (for building high standard), are found compliance to people trying to move behind who is using it.

Was also diagnosed an inadequate circulation in the rooms, the beds and between beds and the wall. But the situation becomes more common in apartment housing and only occurs once in the apartment of high standard.
In the bathrooms usually the major cause of problems encountered is related to the use of the sink with respect to the turning of the door as well as the movement of another person behind whoever uses it. They also found a problem in movement between the vessel and the wall, this problem is directly related to the minimum allowed by design COUP (Code of Urban Planning, Works and postures of the city of Caruaru) which is the insertion of a circumference of 1.30 in diameter Additional bathrooms and a circumference of $90 \mathrm{~cm}$ in diameter.

On the terraces, as it is usually very reduced environments, the great difficulty was the movement between the chairs and table when these are being used.

For service areas, which was considered as the best method was the circulation of the apartment of high standard, though the housing that has integrated service area to the kitchen had a better performance than the service area and kitchen buildingaverage standard. This shows that the adjustments are independent of the movement to some extent, a large space, because even the kitchen of the apartment being less popular than the average standard of the apartment, it presented a more adequate circulation.

For the quarter, which only were found in apartments and high average standard, which was better evaluated on the movement, was the room service apartment of average standard.

\section{Conclusions and final considerations}

On the method, one can conclude that he was able to identify the most critical points of attention and adequate internal circulation of three horizontal apartments evaluated by performing a diagnostic color that creates a hierarchy of more serious problems and more frequent each environment.

The analysis of the circulation time of each apartment was relatively quick, but this time depends on the size of the apartment and skill in Auto CAD software of who performs the simulation of the circulation. Thus, you should think about creating a software capable of performing this simulation more quickly so that this methodology can be applied by designers projectual still at the stage, making the circulation of appropriate environments to the anthropometric measures.

One drawback of the method was found that the proportions of anthropometric models are not the result of national surveys were based on anthropometric dimensions of the models Panero and Zelnik 
(2002), this way even though the literature consider valid the use of these measures, the most would be appropriate to use measures of the population. Therefore it is essential that analyzes anthropometric for Brazil to have anthropometric data that can be used not only in the designs of environments but also in the design of artifacts in general.

Regarding the internal horizontal circulations of the apartments valued at Caruaru, there is a lack of concern for designers, builders and the Code of Works with minimum human needs. Since these professionals are also responsible for the welfare of users.

One can see that the constraints of inadequate circulation not only to get stuck with small size apartments. This study can be seen that the lack of concern of the designers with the anthropometric measurements are present even in apartments of different standards. Thus, anthropometric mismatches circulation can not be attributed only to small rooms.

With the evaluation of the apartments could be seen that the major problem encountered was not only the reduction of the environment, because even in areas considered spacious anthropometric mismatches were found regarding the circulation. So the problem encountered is related to projects of ambience and faulty design of spaces that are not concerned with human measures.

The Code of Urbanism, Construction and postures of the City of Caruaru, minimum measures that allows users to generate constraints, make it virtually impossible to insert fittings and furniture that is capable of generating an adequate circulation anthropometric measurement.

The search results can be used for architects, engineers, designers and professionals responsible for the design of spaces and environments to be vigilant to the most critical points presented here found. The intention is that these professionals use the data as a source of reference to predict and resolve outstanding problems existing in their projects.

Finally, it is recommended that this study be applied during projectual of any apartment, house or even commercial sites to be executed buildings and projects of ambience that have their proper circulation to human factors, in which, as already implemented, are done research with the users to verify that the occurrence of circulation problems, as well as the identification of the service of human needs for movement.

\section{References}

[1] Barros, Bruno (2009). Avaliação Antropométrica de Espaços de Circulação Interna de Ambientes: um método proposto. Anais do $5^{\circ}$ Congresso Internacional de Pesquisa em Design CIPED 2009. Bauru-SP.

[2] Bins Ely, Vera Helena Moro (2004). Ergonomia + Arquitetura: Buscando um melhor desempenho do ambiete físico. In Moraes, Ana Maria de; Amado, Giuseppe. (Orgs.). Coletânia de palestras de convidados internacionais e nacionais; Ergodesign e USIHC. Rio de Janeiro: FAPERJ / iUsEr. P. 167-174.

[3] Boueri Filho, José Jorge. Projeto e Dimensionamento dos Espaços da Habitação. Espaço de Atividades - Livro II 48 p. São Paulo: Estação das Letras e Cores. 2008.

[4] Costa Filho, Lourival Lopes; Maciel, Maria Lecticia; MONTE, Rosamaria do; Martins, Laura Bezerra; SOARES, Marcelo Márcio (2003). Apertamento: Uma Análise das Dimensões Mínimas em Apartamentos. In: Anais do XXIII Encontro Nacional de Engenharia de Produção ENEGEP, Ouro Preto.

[5] Panero, Julius; Zelnik, Martin. O Dimensionamento Humano para Espaços Interiores. 8ª Ed. Mexico, D.F., Gustavo Gili. 2002. 